\title{
Rare Earth Elements determined in Antarctic ice by Inductively Coupled Plasma - Time of Flight, Quadrupole and Sector Field- Mass Spectrometry: an inter-comparison study
}

\author{
D. Dick, A. Wegner, P. Gabrielli ${ }^{+, t}$, U. Ruth, C. Barbante ${ }^{+, \Delta}$, M. Kriews ${ }^{*}$ \\ Alfred Wegener Institute for Polar and Marine Research, Am Handelshafen 12, 27570 \\ Bremerhaven, Germany \\ ${ }^{+}$Institute for the Dynamics of Environmental Processes - CNR, 30123 Venice, Italy \\ ${ }^{\Delta}$ Department of Environmental Sciences, University of Venice, Ca' Foscari, 30123 Venice, \\ Italy \\ ${ }^{\mathrm{t}}$ School of Earth Science and Byrd Polar Research Center, Ohio State University, \\ Columbus, OH 43210-1002, USA
}

\begin{abstract}
Inductively coupled plasma mass spectrometry (ICP-MS) is a suitable tool for multi-element analysis at low concentration levels. Rare earth element (REE) determinations in standard reference materials and small volumes of molten ice core samples from Antarctica have been performed with an ICP-Time of Flight-MS (ICP-TOF-MS) system. Recovery rates for REE in e.g. SPS-SW1 amounted to $\sim 103 \%$, and the relative standard deviations were $3.4 \%$ for replicate analysis at REE concentrations in the lower $n g \mathrm{~L}^{-1}$ range. Analyses of REE concentrations in Antarctic ice core samples showed that the ICP-TOF-MS technique meets the demands of restricted sample mass. The data obtained are in good agreement with ICPQuadrupole-MS (ICP-Q-MS) and ICP-Sector Field-MS (ICP-SF-MS) results. The ICP-TOFMS system determines accurately and precisely REE concentrations exceeding $5 \mathrm{ng} \mathrm{L}^{-1}$ while between 0.5 and $5 \mathrm{ng} \mathrm{L}^{-1}$ accuracy and precision are element dependent.
\end{abstract}

Keywords: ultra trace element analysis, ICP-TOF-MS, rare earth elements, Antarctic ice

\section{Introduction}

Inductively coupled plasma mass spectrometry (ICP-MS) is a powerful technique for analysis of the elemental composition and isotope ratios for diverse kinds of samples (environmental, geological and biological samples). Various techniques for mass selection are used in ICPMS. Sector Field mass spectrometers (SF-MS) [1] and Quadrupole mass spectrometers (QMS) [2] have been the most common MS types used for the analysis of natural samples so far. Both instruments scan one element after another, which is called sequential analysis. Often the number of isotopes analysed is limited owing to small sample volumes and thus short analysis times. In contrast to the sequential MS systems, the Time of Flight-MS (TOF-MS)

\footnotetext{
* Corresponding author tel.: +49-(0)471-4831-1420; fax: +49-(0)471-4831-1149; email: Michael.Kriews@awi.de
} 
analyses in a quasi simultaneous mode [3] as all isotopes are simultaneously extracted from the ion source. This increases the precision and the accuracy of the analysis, which is a particular benefit for isotope ratio measurements [4-6]. Major advantages of such a system are: No limitations on the number of isotopes analysed and fast data acquisition. This latter is important when using sample introduction systems like laser ablation [7] or an inductively coupled heated vaporizer [8] and allows obtaining numerous replicate analyses. In contrast to MS systems analyzing in the sequential mode, for ICP-TOF-MS systems the detection capability is independent of the number of isotopes determined [6]. A brief overview of the application of TOF-MS is provided elsewhere [9]. Until now, only few studies on the use of ICP-TOF-MS for element analysis have been published [7-8, 10-14]. In particular the determination of extreme ultra traces of rare earth elements (REE) has so far been described only rarely [15-16] and only for samples after concentration by a factor of 15 to 22 and by a factor of 500, respectively.

Studies of trace elements in natural samples (e.g. ice cores from polar regions) as indicator of environmental pollution and for paleoclimate research have been performed [17-20]. Owing to large distances between Antarctica and its surrounding continents (South America Antarctica $(\sim 1100 \mathrm{~km})$, South Africa - Antarctica $(\sim 4000 \mathrm{~km})$ and New Zealand / Australia Antarctica $(\sim 2500 \mathrm{~km}, \sim 3000 \mathrm{~km}))$ and because of the shielding circum-Antarctic circulation pattern, Antarctica is the remotest area in the world. This results in very low trace element concentrations. Thus demands are high on sampling of snow and ice cores, on sample preparation and finally on the analysis of low concentrations in limited sample volumes [1-2, 21].

The aim of this work is to assess the accuracy and precision of an ICP-TOF-MS system [7, 12] in determining REE at ultra low concentration levels. The ICP-TOF-MS system was developed at the Institute for Analytical Science in Berlin, supported as a research prototype jointly with Analytik Jena. Reference materials SPS-SW1 and SLRS-4 were analysed. Instrumental detection limits (IDL), the recovery rate and precision, the sample consumption and analysing time are presented. For inter-comparison studies of different MS systems and laboratories, ice core samples drilled within the European Project for Ice Coring in Antarctica (EPICA) $[22,23]$ were analysed by ICP-TOF-MS, ICP-Q-MS and ICP-SF-MS.

\section{Experimental}

\section{Standards and Labware}

At the Alfred Wegener Institute (AWI) in Bremerhaven, Germany, ultrapure water was produced by coupling a reverse osmosis system with a Purelab Ultra system (Elga, High Wycombe, U.K.). Commercially available ICP-MS multi-element stock solutions (10 $\mathrm{mg} \mathrm{L}^{-1}$; Perkin Elmer) were used for external calibration of the ICP-TOF-MS and ICP-Q-MS systems. At the Institute for the Dynamics of Environmental Processes (IDPA) in Venice, Italy, where inter-comparison studies with the ICP-SF-MS were conducted, the ultrapure water was produced by coupling a Milli-Q (Millipore, Bedford, MA) water system with a Purelab Ultra 
system (Elga, High Wycombe, U.K.). Matrix matched calibration was performed at IDPA by spiking different amounts of multi-element standard to a melted surface snow sample. At AWI, all standards were acidified to $\mathrm{pH} 1$ with sub-boiled $\mathrm{HNO}_{3}$ (distilled $65 \% \mathrm{HNO}_{3}$, pro analysis, Merck) and they were spiked with $1 \mu \mathrm{g} \mathrm{L}^{-1} \mathrm{Rh}\left(\mathrm{RhCl}_{3}\right.$, Merck) as internal standard. Eppendorf pipettes with polypropylene (PP) tips were used for sample and standard preparation. Steps for standard preparation were carried out under a clean bench US Class 100 installed in a clean room US class 10000. At AWI, all labware to which samples and standards were exposed were run through a special cleaning procedure (see supplementary material). The cleaning procedure performed at IDPA is described elsewhere [1].

\section{Sample collection and preparation}

\section{Reference material}

Two reference materials were used to validate the quality of the ICP-TOF-MS as well as the ICP-Q-MS measurements: 1) SPS-SW1: Spectrapure Standards AS, Reference Material for measurements of Elements in Surface Waters, 2) SLRS-4: National Research Council Canada, River Water Reference Materials for Trace Metals.

For applicability to the low REE concentrations expected in Antarctic ice the SPS-SW1 standard was diluted by 1:100. REE from La to Nd in SLRS-4 were determined using a 1:10 dilution, while all other REE were determined without any dilution.

\section{Antarctic Ice Core samples}

Within the EPICA two deep ice cores were drilled. One at Kohnen station in Dronning Maud Land (DML) and one at Dome C station (DC). Nine samples from the EPICA-DML (EDML) ice core and eleven samples from EPICA-DC (EDC) were chosen for REE analysis. Sample ages from $14.2 \mathrm{kyr}$ before present (b.p., where present is defined as 1950) to $48.7 \mathrm{kyr}$ b.p. [2425], i.e. all samples originate from the ultimate glacial period. For each sample a section from the inner part of the ice core was obtained for REE determinations to avoid contamination by the drilling fluid (see supplementary material).

At AWI, samples were melted and transferred into pre-cleaned polyfluor alkoxy (PFA) vessels under a clean bench US Class 100 installed in a clean room laboratory US Class 10000. The polystyrene (PS)-vials used for sample storage were rinsed with $10 \mathrm{~mL}$ sub-boiled $\mathrm{HNO}_{3}\left(1 \mathrm{Mol} \mathrm{L}^{-1}\right)$ which was added into the PFA vessels. Samples were concentrated to 0.5 to $2 \mathrm{~mL}$ with a pressure digestion system (Druckaufschlusssystem DAS, Picotrace $\mathrm{GmbH}$, Germany; Figure S2, left side) and digested using $2 \mathrm{~mL}$ sub-boiled $\mathrm{HNO}_{3}$ (distilled $65 \%$, p.a., Merck), $1 \mathrm{~mL}$ sub-boiled HF (40\%, suprapure, Merck) and $2 \mathrm{~mL} \mathrm{H}_{2} \mathrm{O}_{2}$ (30\%, suprapure, Merck) with the same DAS system by changing the top part (Figure S2, right side). Subsequently, samples were concentrated to a maximum volume of $1.75 \mathrm{~mL}$. Detailed information about the concentration and digestion of samples is given as supplementary material (Figure S2, Table S1). Finally, samples were transferred into polypropylene (PP) vials, Rh was added $\left(1 \mu \mathrm{g} \mathrm{L}^{-1}\right)$ and the vials were filled up to a volume of $2 \mathrm{~mL}$ with subboiled $\mathrm{HNO}_{3}\left(1 \mathrm{Mol} \mathrm{L}^{-1}\right)$. On average, samples were concentrated by a factor of 4 . Using 
these $2 \mathrm{~mL}$ samples, REE determinations by ICP-TOF-MS, ICP-Q-MS and ICP-SF-MS were accomplished. Ten blanks ( $2 \mathrm{~mL}$ sub-boiled $\mathrm{HNO}_{3}, 1 \mathrm{~mL} \mathrm{HF}$ and $2 \mathrm{~mL} \mathrm{H}_{2} \mathrm{O}_{2}$ ) were processed in the same way to test the digestion quality.

\section{Instrumentation}

The analytical measurements were conducted at AWI by ICP-TOF-MS (Analytik Jena, Jena, Germany) and ICP-Q-MS (Elan 6000, Perkin Elmer/Sciex, Waltham, Massachusetts). Analyses by ICP-SF-MS (Element2, Thermo Finnigan, Bremen, Germany) were performed at IDPA. The experimental setup for the ICP-TOF-MS is shown elsewhere [12]. The ICP-TOFMS and the ICP-Q-MS were situated in clean room laboratories, US Class 10000; the ICPSF-MS is equipped with a US Class 100 clean bench as a clean sample introduction area.

To minimize spectral interference and oxide-formation, microflow nebulization systems with desolvating units were used (Aridus II (for ICP-TOF-MS), MCN6000 (for ICP-Q-MS), Aridus I (for ICP-SF-MS); all: Cetac Technologies, Omaha, Nebraska). These three systems were equipped with a $100 \mu \mathrm{L} \mathrm{min}{ }^{-1}$ PFA nebulizer, a heated PFA spray chamber, and a heated microporous PTFE membrane. Besides reducing the oxide formation, the signal intensities increased by a factor of $\sim 10$ when compared to analysis with cross flow nebulization for ICPTOF-MS and ICP-Q-MS and by a factor of $\sim 5$ for ICP-SF-MS. The instrument settings (Table 1) and the oxide-forming rates of all systems were optimized daily by tuning with a Ce solution.

The main difference between the three sample introduction systems consists in the installation of the spray chamber with respect to the installation of the membrane. Due to vertically installation of the spray chamber in the MCN6000 and slightly downward tilted position in the Aridus I system, larger droplets might pass towards the membrane leading to less stable signals, when the sample flow is not adjusted carefully. In contrast, the spray chamber is slightly upward tilted in the Aridus II system to disable larger droplets to pass towards the membrane, leading to more stable signals. Moreover, in the Aridus II system the nebulizer and spray chamber are shielded to reduce electrostatic effects. Even if different sample introduction systems were used it was expected that only the relative standard deviation (RSD) of replicate analysis was influenced. 
Table 1: Instrument settings and measurement parameters for the ICP-TOF-MS, ICP-Q-MS and ICP-SF-MS systems and desolvation units.

\begin{tabular}{|c|c|c|c|}
\hline & $\begin{array}{l}\text { Analytik Jena } \\
\text { ICP-TOF-MS }\end{array}$ & $\begin{array}{l}\text { Perkin Elmer/Sciex } \\
\text { Elan6000 } \\
\end{array}$ & $\begin{array}{l}\text { Thermo Finnigan, } \\
\text { Element } 2\end{array}$ \\
\hline \multicolumn{4}{|l|}{$\overline{I C P-M S}$} \\
\hline RF Power (W) & 1050 & 1350 & 1250 \\
\hline Plasma gas $\left(\mathrm{L} \mathrm{min}^{-1}\right)$ & 14.5 & 15 & 15.5 \\
\hline Auxiliary gas $\left(\mathrm{L} \mathrm{min}^{-1}\right)$ & 1.4 & 0.8 & 1.8 \\
\hline Nebulizer gas $\left(\mathrm{L} \mathrm{min}^{-1}\right)$ & 0.98 & 0.62 & $0.8-1.1$ \\
\hline resolution adopted $\left(\mathrm{m} \Delta \mathrm{m}^{-1}\right)$ & 620 & 350 & $\sim 400$ \\
\hline Nebulizer (with desolvatisation) & Aridus II & MCN 6000 & Aridus I \\
\hline Sweep gas $\left(\mathrm{L} \min ^{-1}\right)$ & $4.6-5.0$ & 2.35 & $3.40-4.15$ \\
\hline Nitrogen $\left(\mathrm{mL} \mathrm{min}{ }^{-1}\right)$ & $21-22$ & 12 & $1-18$ \\
\hline $\mathrm{T}$ (spray chamber) $\left({ }^{\circ} \mathrm{C}\right)$ & 110 & 110 & 95 \\
\hline $\mathrm{T}$ (desolvating unit) $\left({ }^{\circ} \mathrm{C}\right)$ & 160 & 160 & 175 \\
\hline Sample uptake $\left(\mu \mathrm{L} \mathrm{min}^{-1}\right)$ & 130 & 100 & 100 \\
\hline \multicolumn{4}{|l|}{ Data aquisition } \\
\hline & from mass & & \\
\hline Isotopes analysed & 7 to 238 & 40 & 19 \\
\hline Replicates & 6 & 3 & 40 \\
\hline Integration time (s) & 7 & 0.1 (each isotope) & 0.01 (each isotope) \\
\hline Sweeps & 175000 & 20 & 30 \\
\hline Measuring time per sample (min) & 1.5 & 7 & 8 \\
\hline Oxides $(\%)$ & $0.2-0.5$ & 0.03 & 0.2 \\
\hline Double charged ions $(\%)$ & $14-15$ & $5-7$ & 3 \\
\hline \multicolumn{4}{|l|}{ miscellaneous } \\
\hline analyzing mode & simultaneous & sequential & sequential \\
\hline dynamic range & 4 & 9 & 9 \\
\hline background cps (REE) & $0.5-1$ & $3-30$ & 0.2 \\
\hline sensitivity $1 \mu \mathrm{g} \mathrm{L}^{-1}$ Indium (cps) & 23000 & 83000 & $\sim 3 \times 10^{6}$ \\
\hline $\begin{array}{r}\left.\text { RSD for Nd }(\%) \text { (conc. } 4-50 \mathrm{ng} \mathrm{L}^{-1}\right) \\
\text { TOF: } n=6 ; \mathrm{Q}: \mathrm{n}=3 ; \mathrm{SF}: \mathrm{n}=40\end{array}$ & 3.2 & 11.5 & 7.1 \\
\hline IDL of REE (ng L $\left.{ }^{-1}\right)$ & $0.3-1$ & $1-3$ & $0.001-0.03$ \\
\hline
\end{tabular}

\section{Results and discussion}

\section{Performance of the ICP-TOF-MS system}

To counteract sensitivity drifts, three calibrations were run every day. The linearity of calibration curves was checked by analysing standards at the end of an analysis cycle. Linearity was ascertained from $1 \mathrm{ng} \mathrm{L}^{-1}$ to $5 \mu \mathrm{g} \mathrm{L}^{-1}$. Seven calibration standards ranging from $1 \mathrm{ng} \mathrm{L}^{-1}$ to $500 \mathrm{ng} \mathrm{L}^{-1}$ were analysed ten times per calibration. The calibration range was chosen according to the concentrations expected in the Antarctic ice samples. Table 2 shows averaged calibration data from five calibrations over two days.

Using the Aridus II as the sample introduction system the sensitivity of the tuned ICP-TOFMS system ranged between 16000 and 32000 counts per second (cps) and $\mu \mathrm{g} \mathrm{L}{ }^{-1}$ depending on the REE (see slope in Table 2), which corresponds to $242 \mathrm{cps}$ and $485 \mathrm{cps} \mathrm{ng}^{-1}$ at a sample consumption of $15.2 \mu \mathrm{L}$ per replicate analysis (175000 Sweeps). A low calibration intercept was obtained for all REE (-121 cps to $92 \mathrm{cps}$ ). Generally the standard deviation (SD) for the intercept was high due to counting statistics which decrease with decreasing element concentrations. The resulting correlation coefficients for REE are higher than 0.9980. No IDL was higher than $1 \mathrm{ng} \mathrm{L}^{-1}$ ( $3 \sigma$ criterion of the blank). For ice samples analyses all signals were 
first normalized to the internal standard and afterwards the normalized blank value was subtracted.

Table 2: ICP-TOF-MS calibration data for the investigations of intercomparison samples. Values were calculated on the basis of 5 different calibrations. Each standard was analysed 10 times per calibration. The slope with its $S D$ in cps $\left(\mathrm{ng} \mathrm{L}^{-1}\right)^{-1}$, the intercept with its $S D$ in cps, the blank and $50 \mathrm{ng} \mathrm{L}^{-1}$ signal with their $S D$ in cps, the correlation coefficient $\left(r^{2}\right)$ and the instrumental detection limit (IDL) in $n g L^{-1}$ are given. Additionally REE concentrations of digested blank samples (in $\mathrm{ng} \mathrm{L}^{-1}$ ) are shown. For calculating element concentration in samples, calibration signals were first normalized to ${ }^{103} \mathrm{Rh}$ and afterwards the normalized blank signals were subtracted.

\begin{tabular}{|c|c|c|c|c|c|c|c|c|}
\hline & $\begin{array}{c}\text { No. of } \\
\text { data points }\end{array}$ & $\begin{array}{l}\text { slope } \pm \text { SD } \\
\left(\operatorname{cps}\left(\mu \mathrm{g} \mathrm{L}^{-1}\right)^{-1}\right)\end{array}$ & $\begin{array}{c}\text { intercept } \pm \text { SD } \\
(\mathrm{cps})\end{array}$ & $\begin{array}{c}\text { blank } \pm \text { SD } \\
(\mathrm{cps})\end{array}$ & $\begin{array}{c}50 \mathrm{ng} \mathrm{L}^{-1} \pm \mathrm{SD} \\
(\mathrm{cps})\end{array}$ & $r^{2}$ & $\begin{array}{c}\mathrm{IDL} \\
\left(\mathrm{ng} \mathrm{L}^{-1}\right) \\
\end{array}$ & $\begin{array}{c}\text { conc. digested } \\
\text { blank samples }\left(\mathrm{ng} \mathrm{L}^{-1}\right)\end{array}$ \\
\hline$\overline{\mathrm{La}}$ & 6 & $27948 \pm 1087$ & $5 \pm 19$ & $31 \pm 6$ & $1363 \pm 101$ & 0.9988 & 0.6 & $0.9 \pm 0.03$ \\
\hline $\mathrm{Ce}$ & 7 & $30553 \pm 2294$ & $-121 \pm 47$ & $38 \pm 9$ & $1260 \pm 122$ & 0.9989 & 0.6 & $3.4 \pm 0.1$ \\
\hline $\operatorname{Pr}$ & 6 & $31525 \pm 1277$ & $0 \pm 24$ & $24 \pm 6$ & $1542 \pm 137$ & 0.9989 & 0.5 & $0.7 \pm 0.01$ \\
\hline $\mathrm{Nd}$ & 5 & $27248 \pm 1425$ & $92 \pm 18$ & $103 \pm 12$ & $1462 \pm 106$ & 0.9980 & 0.8 & $1.9 \pm 0.1$ \\
\hline $\mathrm{Sm}$ & 6 & $16958 \pm 987$ & $56 \pm 10$ & $61 \pm 7$ & $892 \pm 69$ & 0.9987 & 0.9 & $0.4 \pm 0.04$ \\
\hline $\mathrm{Eu}$ & 5 & $29882 \pm 1632$ & $38 \pm 13$ & $46 \pm 7$ & $1539 \pm 126$ & 0.9985 & 0.5 & $0.1 \pm 0.01$ \\
\hline Gd & 5 & $21286 \pm 955$ & $70 \pm 13$ & $78 \pm 8$ & $1140 \pm 71$ & 0.9984 & 0.7 & $0.5 \pm 0.03$ \\
\hline $\mathrm{Tb}$ & 6 & $31998 \pm 737$ & $-3 \pm 21$ & $25 \pm 4$ & $1544 \pm 102$ & 0.9988 & 0.3 & $0.1 \pm 0.01$ \\
\hline Dy & 5 & $21299 \pm 1222$ & $53 \pm 11$ & $59 \pm 7$ & $1122 \pm 80$ & 0.9987 & 0.7 & $0.7 \pm 0.01$ \\
\hline Ho & 5 & $28628 \pm 1585$ & $13 \pm 11$ & $23 \pm 4$ & $1449 \pm 100$ & 0.9986 & 0.3 & $0.1 \pm 0.01$ \\
\hline $\mathrm{Er}$ & 5 & $16880 \pm 1152$ & $32 \pm 6$ & $37 \pm 5$ & $881 \pm 70$ & 0.9988 & 0.7 & $0.3 \pm 0.02$ \\
\hline $\mathrm{Tm}$ & 5 & $28658 \pm 1794$ & $15 \pm 10$ & $23 \pm 4$ & $1455 \pm 112$ & 0.9988 & 0.3 & $0.1 \pm 0.01$ \\
\hline $\mathrm{Yb}$ & 5 & $23954 \pm 1343$ & $70 \pm 14$ & $77 \pm 7$ & $1271 \pm 92$ & 0.9984 & 0.7 & $0.6 \pm 0.04$ \\
\hline $\mathrm{Lu}$ & 6 & $27593 \pm 1240$ & $5 \pm 16$ & $24 \pm 4$ & $1348 \pm 102$ & 0.9992 & 0.4 & $0.2 \pm 0.00$ \\
\hline $\mathrm{Rh}^{*}$ & & & & $12572 \pm 719$ & $12926 \pm 810$ & & & \\
\hline
\end{tabular}

\section{Accuracy and Precision of the ICP-TOF-MS and ICP-Q-MS}

Two reference materials, SPS-SW1 and SLRS-4, were analysed. Certified REE concentrations are only available for SPS-SW1, each concentration amount being $500 \mathrm{ng} \mathrm{L}^{-1}$. Table 3 summarizes all REE concentrations obtained by ICP-TOF-MS and ICP-Q-MS, the certified values for SPS-SW1 as well as the literature data available for SLRS-4 [26]. For SPS-SW1 the concentrations found do not differ significantly from the certified values except for La, Ce, and Dy. Both MS systems showed distinct differences for Dy to the certified values. The concentrations for La and Ce obtained by ICP-TOF-MS were also significantly increased for SLRS-4. For ICP-TOF-MS analysis it was noted that Ba concentrations exceeding $1 \mu \mathrm{g} \mathrm{L}^{-1}(\sim 18000 \mathrm{cps})$ affect the determination of La and Ce. SPS-SW1 contains $50 \mu \mathrm{g} \mathrm{L}^{-1}$ of Ba or, in a 1:100 dilution, only $0.5 \mu \mathrm{g} \mathrm{L}^{-1}$. The influence of this high Ba content should be clarified in further investigations. SLRS-4 contains $12.2 \mu \mathrm{g} \mathrm{L}^{-1}$ of Ba $\left(1.22 \mu \mathrm{g} \mathrm{L}^{-1}\right.$ in a 1:10 dilution) and $\mathrm{La}$ and $\mathrm{Ce}$ analysis are also influenced although not as severely as in SPS-SW1. In general, REE concentrations of SLRS-4 obtained by ICP-TOF-MS, ICP-Q-MS and literature data [26] agree well. In most cases, no significant differences were estimated at the $99 \%$ level of confidence. The RSD of 10 replicate analyses were similar for the two MS systems. Median values were 3.5\% for ICP-TOF-MS analysis (e.g. Ce: 3.4\%, Gd: 2.8\%, Yb: 5.8 ) and $2.5 \%$ for ICP-Q-MS analysis (e.g. Ce: $1.3 \%$, Gd: $4.7 \%$, Yb: $4.2 \%$ ) in a concentration

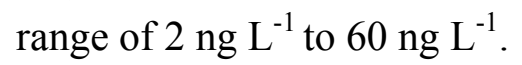


Table 3: REE concentrations in $n g L^{-1}$ with SD (10 replicate measurements) in reference materials SPS-SW1 and SLRS-4 obtained by ICP-TOF-MS and ICP-Q-MS. Recovery rates in \% for reference material SPS-SW1 are shown in brackets below the concentrations obtained by ICP-TOF-MS and ICP-Q-MS. Concentrations of reference materials SPS-SW1 were derived by analysing a 1:100 dilution. REE from La to Nd in SLRS-4 were analysed out of a 1:10 dilution, all other REE were analysed without any dilution.

$\left.\underline{\text { SPS-SW1 (ng L }}{ }^{-1}\right) \quad \underline{\text { SLRS-4 }\left(\text { ng L }^{-1}\right)}$

\begin{tabular}{|c|c|c|c|c|c|c|}
\hline & certified & $\begin{array}{c}\text { ICP-TOF-MS } \\
\text { (recovery rate (\%)) }\end{array}$ & ICP-Q-MS & ICP-TOF-MS & ICP-Q-MS & reference $[26]$ \\
\hline $\mathrm{La}$ & $500 \pm 10$ & $\begin{array}{l}586 \pm 10 \\
(117.3)\end{array}$ & $\begin{array}{l}495 \pm 16 \\
(98.9)\end{array}$ & $304 \pm 4$ & $278 \pm 4$ & $287 \pm 7$ \\
\hline $\mathrm{Ce}$ & $500 \pm 10$ & $\begin{array}{l}581 \pm 22 \\
(116.1)\end{array}$ & $\begin{array}{l}516 \pm 10 \\
(103.3)\end{array}$ & $411 \pm 12$ & $361 \pm 2$ & $360 \pm 11$ \\
\hline $\operatorname{Pr}$ & $500 \pm 10$ & $\begin{array}{l}516 \pm 17 \\
(103.2)\end{array}$ & $\begin{array}{l}510 \pm 8 \\
(101.9)\end{array}$ & $77 \pm 1$ & $67 \pm 2$ & $69 \pm 2$ \\
\hline $\mathrm{Nd}$ & $500 \pm 10$ & $\begin{array}{l}505 \pm 37 \\
(101.1)\end{array}$ & $\begin{array}{l}510 \pm 8 \\
(102.0)\end{array}$ & $260 \pm 10$ & $262 \pm 10$ & $269 \pm 13$ \\
\hline Sm & $500 \pm 10$ & $\begin{array}{l}497 \pm 17 \\
(99.4)\end{array}$ & $\begin{array}{l}497 \pm 1 \\
(99.4)\end{array}$ & $64 \pm 2$ & $57 \pm 3$ & $57 \pm 2$ \\
\hline $\mathrm{Eu}$ & $500 \pm 10$ & $\begin{array}{l}497 \pm 14 \\
(99.4)\end{array}$ & $\begin{array}{l}510 \pm 8 \\
(102.1)\end{array}$ & $12 \pm 0.3$ & $11 \pm 1$ & $8 \pm 0.5$ \\
\hline $\mathrm{Gd}$ & $500 \pm 10$ & $\begin{array}{l}490 \pm 10 \\
(98.0)\end{array}$ & $\begin{array}{l}513 \pm 8 \\
(102.6)\end{array}$ & $37 \pm 1$ & $40 \pm 3$ & $34 \pm 2$ \\
\hline $\mathrm{Tb}$ & $500 \pm 10$ & $\begin{array}{l}482 \pm 13 \\
(96.3)\end{array}$ & $\begin{array}{l}506 \pm 6 \\
(101.1)\end{array}$ & $4 \pm 0.2$ & $5 \pm 0.4$ & $4 \pm 0.3$ \\
\hline Dy & $500 \pm 10$ & $\begin{array}{l}603 \pm 5 \\
(120.7)\end{array}$ & $\begin{array}{l}852 \pm 21 \\
(170.4)\end{array}$ & $22 \pm 1.9$ & $24 \pm 0.4$ & $24 \pm 1.4$ \\
\hline Но & $500 \pm 10$ & $\begin{array}{l}486 \pm 17 \\
(97.3)\end{array}$ & $\begin{array}{l}519 \pm 13 \\
(103.8)\end{array}$ & $5 \pm 0.2$ & $4 \pm 0.5$ & $5 \pm 0.3$ \\
\hline $\mathrm{Er}$ & $500 \pm 10$ & $\begin{array}{l}461 \pm 36 \\
(92.2)\end{array}$ & $\begin{array}{l}498 \pm 5 \\
(99.6)\end{array}$ & $12 \pm 0.4$ & $16 \pm 0.9$ & $13 \pm 0.5$ \\
\hline $\mathrm{Tm}$ & $500 \pm 10$ & $\begin{array}{l}\quad 490 \pm 20 \\
(98.0)\end{array}$ & $\begin{array}{l}510 \pm 5 \\
(102.0)\end{array}$ & $2 \pm 0.1$ & $2 \pm 0.3$ & $2 \pm 0.1$ \\
\hline $\mathrm{Yb}$ & $500 \pm 10$ & $\begin{array}{l}503 \pm 28 \\
(100.7)\end{array}$ & $\begin{array}{l}503 \pm 16 \\
(100.6)\end{array}$ & $11 \pm 0.7$ & $11 \pm 0.6$ & $12 \pm 0.3$ \\
\hline $\mathrm{Lu}$ & $500 \pm 10$ & $\begin{array}{l}490 \pm 22 \\
(98.1)\end{array}$ & $\begin{array}{r}517 \pm 3 \\
(103.3)\end{array}$ & $3 \pm 0.1$ & $2 \pm 0.2$ & $2 \pm 0.1$ \\
\hline
\end{tabular}

\section{Interference studies}

To reduce problems with spectral interferences in ICP-TOF-MS, for REE mainly represented by oxides, the described desolvation unit was used. Additionally, equations were compiled to calculate the residual fractions of the interfering species. Equation 1, for example, can be used to correct isobaric interferences of ${ }^{142} \mathrm{Nd}$ by ${ }^{142} \mathrm{Ce}$, while the correction of the ${ }^{155} \mathrm{Gd}$ signal in equation 2, is shown as an example for the correction of the spectral interferences:

$$
\begin{aligned}
& { }^{142} \mathrm{Nd}_{\text {corr }}={ }^{142} \mathrm{Nd}-\frac{11.08}{88.48} \cdot{ }^{140} \mathrm{Ce} \\
& { }^{155} \mathrm{Gd} d_{\text {corr }}={ }^{155} \mathrm{Gd}-0.9967 \cdot{ }^{139} \mathrm{La} \cdot \mathrm{MO}^{+}
\end{aligned}
$$

Isobaric interferences are present for isotopes such as ${ }^{142} \mathrm{Nd}\left({ }^{142} \mathrm{Ce}, 11.08 \%\right),{ }^{144} \mathrm{Nd}\left({ }^{144} \mathrm{Sm}\right.$, $3.1 \%$ ) and ${ }^{164} \mathrm{Dy}\left({ }^{164} \mathrm{Er}, 1.61 \%\right)$. Corrections due to oxide formation must be applied (equation 2) for isotopes exceeding a mass of 154 . Tests showed in fact that $\mathrm{BaO}^{+}$species are not present and therefore oxide corrections for masses between 146 and 154 can be neglected. Table S2 shows the analysed isotopes with their natural abundances and potential interfering species. When possible, several isotopes of one element were determined to check the 
efficacy of the corrections. The very good agreement among concentrations obtained by two or more different isotopes suggests that isobaric and spectral interferences were successfully corrected or rendered negligible.

Ba concentrations exceeding $1 \mu \mathrm{g} \mathrm{L}^{-1}$ lead to high background signals (10 cps; usually $0.5-$ $1 \mathrm{cps}$ ) in the ICP-TOF-MS for mass 139 (La) and 140 (Ce). Therefore, in the majority of cases, $\mathrm{La}$ and $\mathrm{Ce}$ concentrations were obtained from the diluted samples. Successfully tested equations are integrated within the evaluation system of the ICP-Q-MS systems. REE interference studies of the ICP-SF-MS system used at IDPA are reported in [1].

\section{Long term stability of the ICP-TOF-MS}

Two hundred measurements, each with $7 \mathrm{~s}$ integration time and $5.4 \mathrm{~s}$ relaxation time amounting to a total of 41.3 minutes, have been conducted for long term stability tests of the ICP-TOF-MS system. Several standards were tested and showed very good long term stability. For example, the RSD of Er, the REE with the lowest signal sensitivity, was: $12.9 \%$ for a blank standard (37 cps), $11.7 \%$ for a $1 \mathrm{ng} \mathrm{L}^{-1}$ standard $\left(52 \mathrm{cps}\right.$ ), $5.9 \%$ for a $10 \mathrm{ng} \mathrm{L}^{-1}$ standard (180 cps), 3.4\% for a $0.1 \mu \mathrm{g} \mathrm{L}^{-1}$ standard (1675 cps), $1.0 \%$ for a $0.5 \mu \mathrm{g} \mathrm{L}^{-1}$ standard (9450 cps) and $0.8 \%$ for a $1 \mu \mathrm{g} \mathrm{L}^{-1}$ standard $(20230 \mathrm{cps})$. This is in a good agreement with data obtained by coupling the Aridus II to a Quadrupole ICP-MS system [27].

\section{Concentrations in Antarctic ice core samples}

An inter-comparison exercise between three different ICP-MS systems was carried out to illustrate the performance of the ICP-TOF-MS. Figure 1 shows correlation diagrams for REE concentrations obtained by the three different MS systems. For the linear fit function the uncertainties linked to each REE concentration were taken as weighting parameters (error $=S D / \sqrt{n}, \mathrm{n}=$ number of replicate analysis). The intercept was assumed to be zero. Table S3 lists all concentration data. All concentrations of Antarctic samples were calculated accounting for concentration after digestion (on average a factor of 4) and after subtracting blank.

In general SDs obtained by ICP-Q-MS were much higher compared to the other two MS systems. However, ICP-Q-MS data agreed very well with ICP-SF-MS results. ICP-TOF-MS data were on average slightly higher than concentrations obtained by ICP-Q-MS and on average slightly lower when compared to ICP-SF-MS. Diagrams illustrating ICP-TOF-MS data show on average stronger deviation from the linear fit curve at lower concentrations than the correlation diagrams comparing ICP-SF-MS and ICP-Q-MS data.

For interpretation of correlation diagrams the concentration factor has to be taken into account. Concentrations analysed were about a factor of four higher than concentrations shown in Figure 1 and Table S3. Calculated concentrations range between 0.6 to $260 \mathrm{ng} \mathrm{L}^{-1}$ for light REE (LREE: La - Sm) and between 0.08 to $35 \mathrm{ng} \mathrm{L}^{-1}$ for heavy REE (HREE: Eu $\mathrm{Lu})$. Concentrations of glacial samples from the EDC ice core samples analysed previously [1] agree very well with data obtained in this study.

The lowest La concentrations analysed in this study amount to $30 \mathrm{ng} \mathrm{L}^{-1}$ (Figure 1A). La concentrations below $40 \mathrm{ng} \mathrm{L}^{-1}$ showed strong deviation from the linear fit function in the 
correlation diagrams illustrating ICP-TOF-MS data. La concentrations obtained by the ICPTOF-MS system for EDML samples from $904 \mathrm{~m}, 953 \mathrm{~m}$ and $1202 \mathrm{~m}$ depth and the EDC sample from $460.9 \mathrm{~m}$ depth were higher than for the other systems, whereas lower concentrations were obtained for one EDML sample (1403 m depth) and one EDC sample (411.4 $\mathrm{m}$ depth). La concentrations differed from each other for the EDML sample from $1102 \mathrm{~m}$ depth for all MS systems. In general, Eu concentrations obtained by ICP-TOF-MS measurements seem to be overestimated, as shown by low slope values $(\mathrm{m}<0.7$, Figure $1 \mathrm{~F})$. The ICP-TOF-MS system yielded values of $\mathrm{Pr}, \mathrm{Nd}, \mathrm{Sm}$ and $\mathrm{Eu}$ which were a factor of 2 higher for the EDC sample from $405.9 \mathrm{~m}$ depth and a factor of 2 up to 10 higher for Sm, Eu, $\mathrm{Gd}$ and $\mathrm{Tb}$ for the EDC sample from $422.4 \mathrm{~m}$ depth. Concentrations obtained by the ICP-QMS system were higher by a factor of 2 up to 3 for the EDML sample from $1302 \mathrm{~m}$ depth and shows higher values for all elements for the EDC samples from $442.2 \mathrm{~m}$ and $451.6 \mathrm{~m}$ depth. Higher concentrations were found by ICP-SF-MS for the EDML sample from $1102 \mathrm{~m}$ depth. The Student T-Test was used to compare REE concentrations for all 20 samples (99\% significance level). Comparison of ICP-TOF-MS concentrations with ICP-Q-MS concentrations showed that most of the calculated REE concentrations were not significantly different. However, the conformity between the ICP-Q-MS and ICP-SF-MS systems is better than between the ICP-TOF-MS and ICP-SF-MS systems. The reason for these differences might be that Ba concentrations influence the ICP-TOF-MS determination of La and Ce and that very low HREE concentrations were analysed.

All REE concentrations shown in Figure 1 and Table S3 were about a factor of 5 up to 90 higher than in the digested blank samples. For Antarctic ice core samples the results from the ICP-TOF-MS system were similar to those of the ICP-Q-MS and ICP-SF-MS for concentration levels down to: La: $40 \mathrm{ng} \mathrm{L} \mathrm{L}^{-1}$, Ce: $40 \mathrm{ng} \mathrm{L}^{-1}$, Pr: $7 \mathrm{ng} \mathrm{L}^{-1}, \mathrm{Nd}: 20 \mathrm{ng} \mathrm{L}^{-1}$, Sm: $4 \mathrm{ng} \mathrm{L}{ }^{-1}$, Gd: 3 ng L ${ }^{-1}$, Tb: 1 ng L ${ }^{-1}$, Dy: 3 ng L ${ }^{-1}$, Ho: 1.5 ng L ${ }^{-1}$, Er: 2 ng L ${ }^{-1}$, Tm: 0.8 ng L $^{-1}$, Yb: $2 \mathrm{ng} \mathrm{L}^{-1}$ and $\mathrm{Lu} 0.5 \mathrm{ng} \mathrm{L}^{-1}$. Eu concentrations obtained by the ICP-TOF-MS system deviated systematically from concentrations obtained by the other systems. 



conc. ICP-TOF-MS (ng L ${ }^{-1}$ )

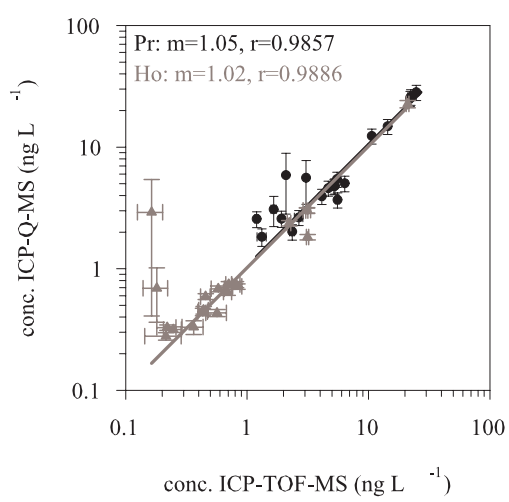

conc. ICP-TOF-MS (ng L ${ }^{-1}$ )
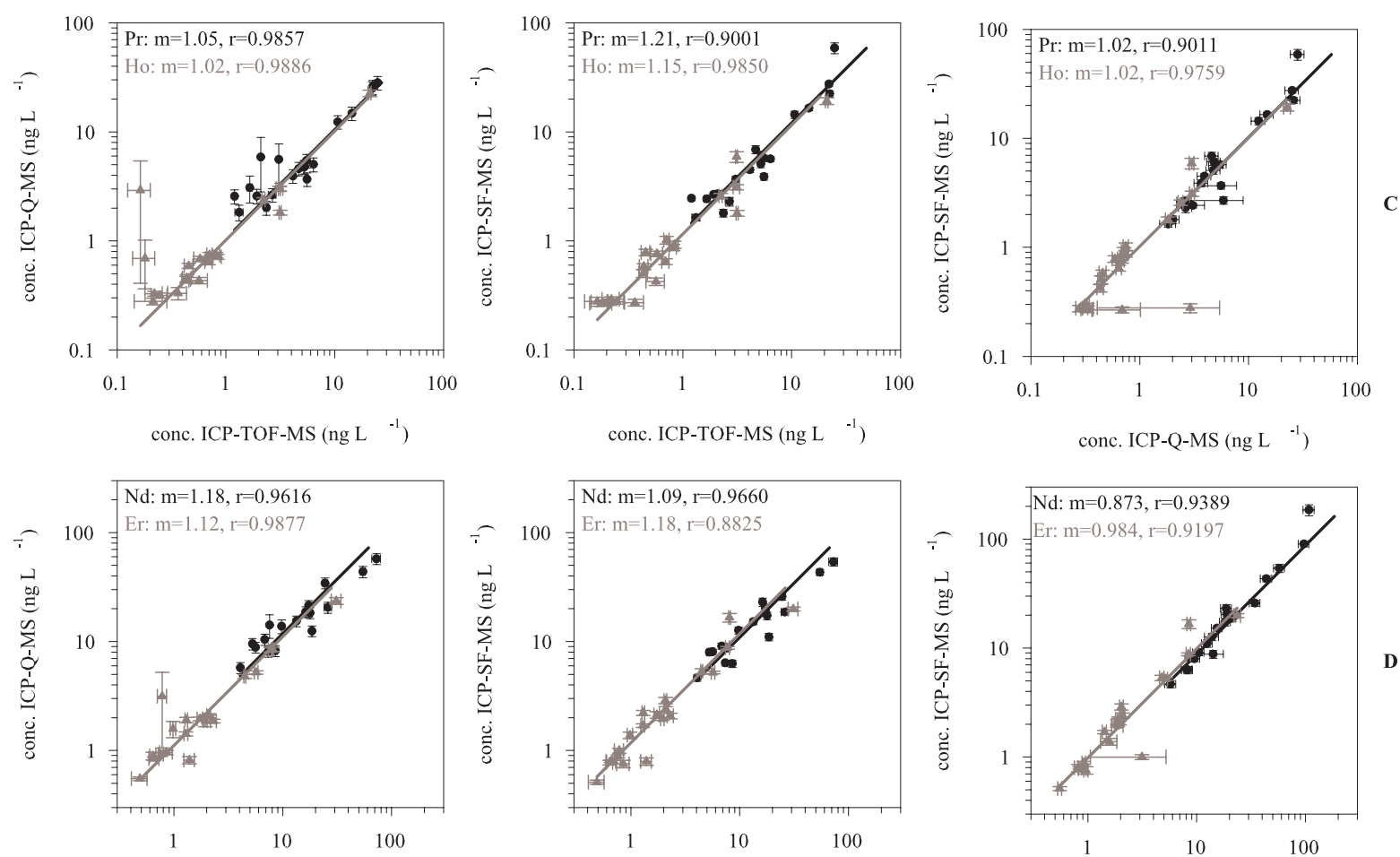

conc. ICP-TOF-MS (ng L ${ }^{-1}$ )



conc. ICP-Q-MS (ng L $\left.{ }^{-1}\right)$

Figure 1: REE concentrations with $S D$ in $n g L^{-1}$ in Antarctic ice core samples plotted as ICP-Q-MS concentrations vs. ICP-TOF-MS concentrations, ICP-SF-MS concentrations vs. ICP-TOF-MS concentrations and ICP-SF-MS concentrations vs. ICP-Q-MS concentrations with associated parameters for a linear fit $(y=m \cdot x$, Assumption: intercept $=0$ ). Errors of each measurement were taken as weighting parameters (error $=S D / \sqrt{n}, n=$ replicate analysis). 

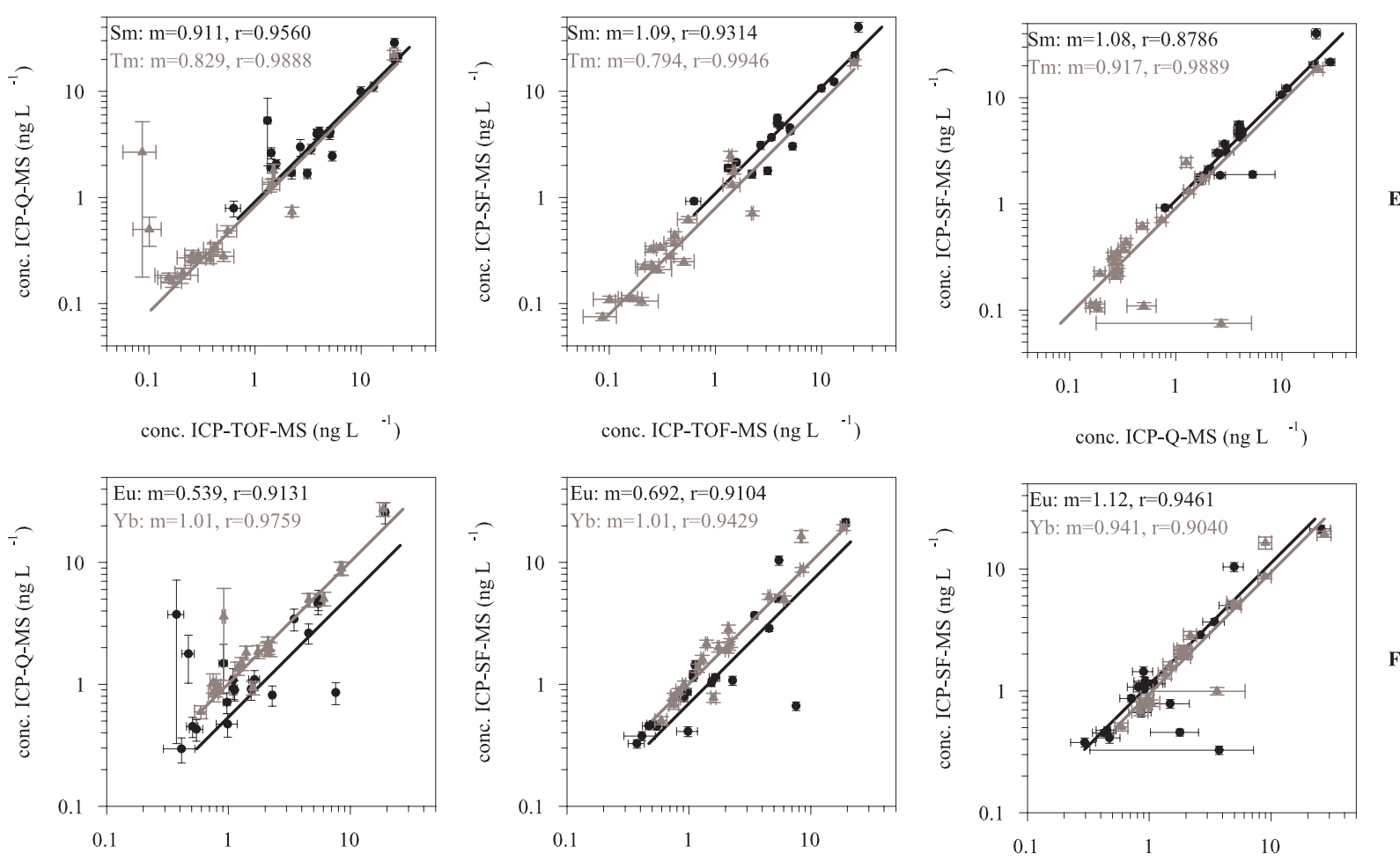

conc. ICP-TOF-MS (ng L $\left.{ }^{-1}\right)$



conc. ICP-Q-MS (ng L $\left.{ }^{-1}\right)$

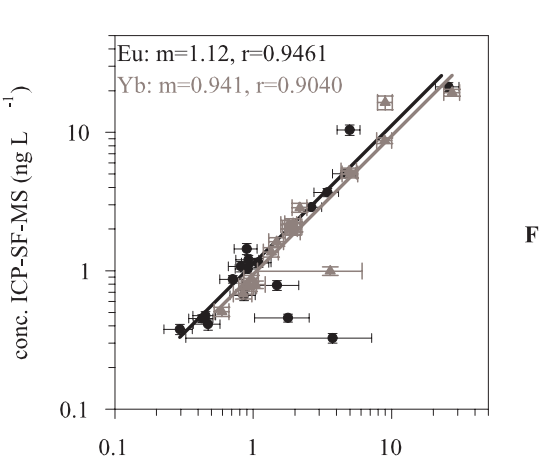

conc. ICP-TOF-MS (ng L $\left.{ }^{-1}\right)$
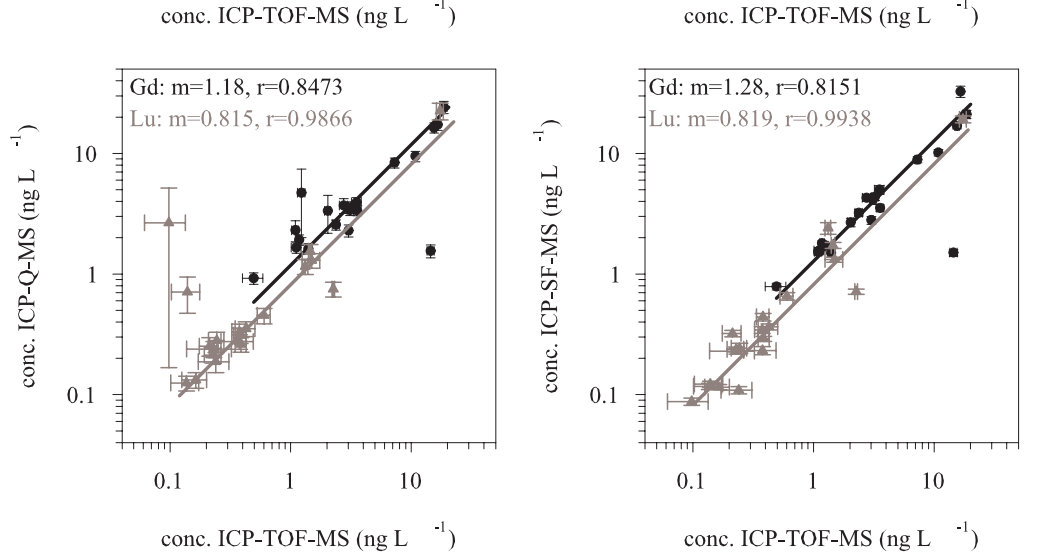

conc. ICP-Q-MS (ng L ${ }^{-1}$ )

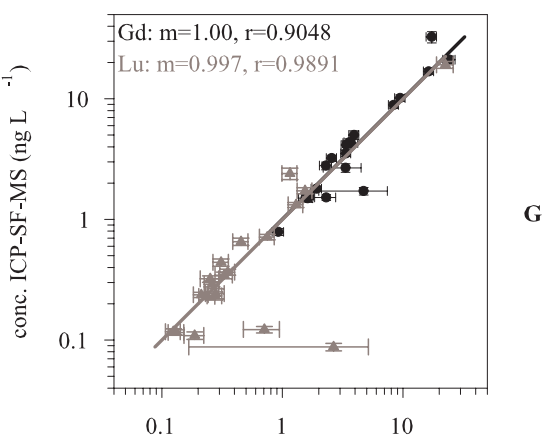

conc. ICP-Q-MS (ng L ${ }^{-1}$ )

Figure 1: continued

\section{Comparison of ICP-MS systems}

Table 1 shows the most important parameters for the ICP-TOF-MS, ICP-Q-MS and ICP-SFMS systems used in this study. The simultaneous analysing mode of the ICP-TOF-MS leads to several advantages including (i) no limitation on the number of analysed isotopes and (ii) its analysis time when compared to other ICP-MS techniques. While the ICP-TOF-MS system needs 1.5 minutes per sample to analyse the mass range from ${ }^{7} \mathrm{Li}$ to ${ }^{238} \mathrm{U}$ (6-fold analysis, 175000 sweeps), the ICP-Q-MS needs 7 minutes for 40 isotopes (3-fold analysis, 20 sweeps) and the ICP-SF-MS needs 8 minutes for 19 isotopes (40-fold analysis, 30 sweeps). Hence the ICP-TOF-MS system requires the lowest sample consumption. However, for the ICP-SF-MS system background signals below $0.2 \mathrm{cps}$ and high sensitivity lead to very low IDL (0.001$\left.0.03 \mathrm{ng} \mathrm{L}^{-1}\right)$. The signal to noise ratio for ICP-TOF-MS and ICP-Q-MS is much lower (31000 and 4900, respectively), consequently higher IDL are observed $\left(0.3-1 \mathrm{ng} \mathrm{L}{ }^{-1} ; 1-3 \mathrm{ng} \mathrm{L}^{-1}\right)$. 


\section{Conclusions}

REE analysis of standard reference materials showed that the ICP-TOF-MS system is best suited for the determination of trace elements with concentrations up to $500 \mathrm{ng} \mathrm{L}^{-1}$. The accuracy and precision found for the reference standard SPS-SW1 are very good. The study of reference materials and inter-comparison exercise between ICP-TOF-MS (Analytik Jena AG), ICP-Q-MS (Elan6000 PerkinElmer/Sciex) and ICP-SF-MS (Element 2, Thermo Finnigan) systems showed that the ICP-TOF-MS system determines accurately and precisely REE concentrations exceeding $5 \mathrm{ng} \mathrm{L}^{-1}$ and that the accuracy and precision between 0.5 and $5 \mathrm{ng} \mathrm{L}^{-1}$ is element dependent. The data indicate that the ICP part of the system is not ideal. It is therefore expected that with improved plasma conditions the ICP-TOF-MS technique may become a very attractive alternative to the ICP-Q-MS and ICP-SF-MS techniques. In general, the expected REE concentrations and the available sample volume can define the kind of ICPMS to be chosen for analysis. The ICP-SF-MS is the most sensitive method for REE determination and therefore it is recommended when the concentration range is unknown or the sample amount is very small. However, in practical analysis the IDL, resolution on interferences, sample throughput, sample consumption, analytical stability and cost are also important parameters which influence the choice of the ICP-MS system.

\section{Acknowledgement}

This work is a contribution to the European Project for Ice Coring in Antarctica (EPICA), a joint European Science Foundation/European Commission scientific programme, funded by the EU and by national contributions from Belgium, Denmark, France, Germany, Italy, the Netherlands, Norway, Sweden, Switzerland and the United Kingdom. The main logistical support was provided by IPEV and PNRA (at Dome C) and AWI (at Dronning Maud Land). This is EPICA publication 200. Special thanks to J-R. Petit, B. Delmonte, M. Bigler and F. Lambert for sample preparation (Antarctic ice cores). The authors would like to thank G. Schlemmer, E. Thamm (both Analytik Jena), F. Wilhelms, J. Schwarz (both AWI) and C. Lüdke for discussion and comments that improved the manuscript. We thank the two anonymous reviewers for constructive criticism.

\section{Supplementary Material}

In the supplementary material information about the cleaning procedure of labware at AWI, the EPICA ice core samples and the separation of the samples used for ICP-MS analysis from the inner part of the ice cores are provided. The concentration and digestion of Antarctic ice core samples is shown in Figure S1 and Table S1. Table S2 shows the determined REE isotopes with natural abundances and potential interference species, which are taken into account for evaluating ICP-TOF-MS data. Table S3 lists all concentration data, with SD, of Antarctic ice core samples obtained by ICP-TOF-MS, ICP-Q-MS and ICP-SF-MS analysis. 


\section{Reference}

[1] P. Gabrielli, C. Barbante, C. Turetta, A. Marteel, C. Boutron, G. Cozzi, W. Cairns, C. Ferrari, P. Cescon, Anal. Chem., 78 (2006) 1883.

[2] G. Tao, R. Yamada, Y. Fujikawa, A. Kudo, J. Zheng, D.A. Fisher, R.M. Koerner, Talanta, 55 (2001) 765.

[3] P.P. Mahoney, S.J. Ray, G.M. Hieftje, Focal Point, 51 (1) (1997) 16A.

[4] K. Benkhedda, H.G. Infante, F.C. Adams, Anal. Chim. Acta, 506 (2004) 137.

[5] X. Tian, H. Emteborg., M. Barbaste, F.C. Adams, JAAS, 15 (2000) 829.

[6] M.V. Peláez, J.M.Costa-Fernández, A. Sanz-Medel, JAAS, 17 (2002) 950.

[7] E. Hoffmann, C. Lüdke, J. Skole, H. Stephanowitz, J. Wollbrandt, W. Becker, Spectrochim. Acta Part B, 57 (10) (2002) 1535.

[8] C. Lüdke, J. Skole, K. Taubner, M. Kriews, Spectrochim. Acta Part B, 60 (11) (2005) 1412.

[9] M. Balcerzak, Anal. Sci., 19 (2003) 979.

[10] N.H. Bings, J.M. Costa-Fernandez, J.P. Guzowski, A.M. Leach, G.M. Hieftje, Spectrochim. Acta Part B, 55 (7) (2000) 767.

[11] N.H. Bings, Nachrichten aus der Chemie, 49(9) (2001) 1069.

[12] E. Hoffmann, C. Lüdke, Spectrosc. Eur., 17 (No.1) (2005) 20.

[13] X. Tian, H. Emteborg, F.C. Adams, JAAS, 14 (1999) 1807.

[14] R.E. Sturgeon, J.W.H. Lam, A. Saint, JAAS, 15 (2000) 607.

[15] K. Benkhedda, H.G. Infante, F.C. Adams, Trends in analytical Chemistry, 21 (5) (2002) 332.

[16] S.N. Willie, R.E. Sturgeon, Spectrochim. Acta, 56B (2001) 1707.

[17] M. Revel-Rolland, P. De Deckker, B. Delmonte, P.P. Hesse, J.W. Magee, I. BasileDoelsch, F. Grousset, D. Bosch, EPSL, 249 (2006) 1.

[18] M. Legrand, P. Mayewski, Rev. Geophys., 35 (1997) 219.

[19] E. Wolff, H. Fischer, F. Fundel, U. Ruth, B. Twarloh, G.C. Littot, R. Mulvaney, R. Röthlisberger, M. de Angelis, C.F. Boutron, M. Hansson, U. Jonsell, M.A. Hutterli, F. Lambert, P. Kaufmann, B. Stauffer, T.F. Stocker, J.P. Steffensen, M. Bigler, M.L. Siggaard-Andersen, R. Udisti, S. Becagli, E. Castellano, M. Severi, D. Wagenbach, C. Barbante, P. Gabrielli, V. Gaspari, Nature, 440 (2006) 491.

[20] I. Basile, F.E. Grousset, M. Revel, J.R. Petit, P.E. Biscaye, N.I. Barkov, EPSL, 146 (1996) 573.

[21] S. Hong, J.P. Candelone, C. Turetta, C.F. Boutron, EPSL, 143 (1996) 233. 
[22] EPICA Community Members, Nature, 444 (2006) 195.

[23] EPICA Community Members, Nature, 429 (2004) 623.

[24] U. Ruth, J.M. Barnola, J. Beer, M. Bigler, T. Blunier, E. Castellano, H. Fischer, F. Fundel, P. Huybrechts, P. Kaufmann, S. Kipfstuhl, A. Lambrecht, A. Morganti, H. Oerter, F. Parrenin, O. Rybak, M. Severi, R. Udisti, F. Wilhelms, E. Wolff, Clim. Past, 3 (2007) 475.

[25] L. Augustin, J. Jouzel, PANGAEA, doi:10.1594/PANGAEA.198743, http://store.pangaea.de/Projects/EPICA/EDC_descr.pdf (2004).

[26] D. Yeghicheyan, J. Carignan, M. Valladon, M. B. Le Coz, F. Le Cornec, M. CastrecRouelle, M. Robert, L. Aquilina, E. Aubry, C. Churlaud, A. Dia, S. Deberdt, B. Dupré, R. Freydier, G. Gruau, O. Hénin, A.M. de Kersabiec, J. Macé, L. Marin, N. Morin, P. Petitjean, E. Serrat, Geostand. Geoanal. Res., 25 (2-3) (2001) 465.

[27] CETAC, http://www.cetac.com/pdfs/Tech\%20Note01_Aridus\%20II.pdf (08.05.2008). 


\section{Supplementary Material}

\section{Cleaning procedure of labware performed at the AWI}

At AWI, all labware to which samples and standards were exposed were run through a special cleaning procedure

- $\quad 1$ week treatment with 3\% Mucasol solution (Merck) to degrease all labware, followed by rinsing of all parts with ultrapure water

- $\quad 1$ week treatment with 1:4 diluted $\mathrm{HCl}$ (30\%, suprapure, Merck), followed by rinsing of all parts with ultrapure water

- 1 week treatment with 1:4 diluted HNO3 (distilled 65\%, p.a., Merck), followed by rinsing of all parts with ultrapure water

- $\quad 1$ week treatment with 1:10 diluted HNO3 (65\%, suprapure, Merck), followed by rinsing of all parts with ultrapure water

- $\quad$ Drying of all parts in a clean room US Class 10000 under a clean bench, US Class 100

- $\quad$ Packing of all parts in 2 polyethylene (PE) bags for storage

\section{Information on ice core samples and separation of the inner part of the ice core}

Within EPICA, a $2774.15 \mathrm{~m}$ long ice core (diameter: $98 \mathrm{~mm}$ ) was drilled in a fluid filled hole at Kohnen station (Dronning Maud Land (DML), location: $75^{\circ} 00^{\prime} \mathrm{S}, 0^{\circ} 04^{\prime} \mathrm{E}$ ). A $3189.45 \mathrm{~m}$ long ice core (diameter: $98 \mathrm{~mm}$ ) was drilled in a fluid filled hole at EPICA Dome C station (location: $75^{\circ} 06^{\prime} \mathrm{S}, 123^{\circ} 21^{\prime} \mathrm{E}$ ) [1-2]. Samples from Kohnen station are called EDML samples and samples from Dome $\mathrm{C}$ station are referred to as EDC samples. 9 samples from the EDML ice core and 11 samples from the EDC ice core were chosen for REE analysis. All samples originate from glacial times. Samples from Kohnen station cover the period from $16.6 \mathrm{kyr}$ before present (b.p., where present is defined as 1950) to 48.7 kyr b.p. [3]. The top of the youngest Dome $\mathrm{C}$ ice core sample was $14.2 \mathrm{kyr}$ old and the bottom of the oldest ice core was 21.5 kyr old [4].

A section from the inner part of the ice core was available for REE analysis. From the top of each ice-core sample a $30 \mathrm{~cm}$ long section was cut using a band saw, stored in a cold room at $-20^{\circ} \mathrm{C}$ at the Laboratoire de Glaciologie et Geophysique de 1'Environment (Grenoble, France) and used for further sample preparation steps. The sample surface was decontaminated in a first step by sawing $1 \mathrm{~cm}$ off the surface with a band saw. The $30 \mathrm{~cm}$ long section was divided into three $10 \mathrm{~cm}$ long parts. Each part was rinsed with 1 to $2 \mathrm{~L}$ ultrapure water three times. In consequence of this procedure the weight of each part was reduced by $50 \%$. The three parts of each section were placed in pre-cleaned high density polyethylene (HDPE) bottles and melted at room temperature. Samples were dispersed by pivoting; aliquots were filled in polystyrene (PS) vials and finally stored at $-20^{\circ} \mathrm{C}$. 


\section{Reference}

[1] EPICA Community Members, Nature, 444 (2006) 195.

[2] EPICA Community Members, Nature, 429 (2004) 623.

[3] U. Ruth, J.M. Barnola, J. Beer, M. Bigler, T. Blunier, E. Castellano, H. Fischer, F. Fundel, P. Huybrechts, P. Kaufmann, S. Kipfstuhl, A. Lambrecht, A. Morganti, H. Oerter, F. Parrenin, O. Rybak, M. Severi, R. Udisti, F. Wilhelms, E. Wolff, Clim. Past, 3 (2007) 475.

[4] L. Augustin, J. Jouzel, PANGAEA, doi:10.1594/PANGAEA.198743, http://store.pangaea.de/Projects/EPICA/EDC_descr.pdf (2004).


Figure S1: Left: Experimental setup for concentration of liquid samples before the addition of acids and after acid digestion. Right: Experimental setup for the acid digestion of Antarctic ice core samples. 
Table S1: Digestion programme of Antarctic ice core samples.

Concentration of samples before digestion

\begin{tabular}{ccccc} 
Programme & heating plate & time (hours) & command & Temperature $\left({ }^{\circ} \mathrm{C}\right)$ \\
\hline concentration & bottom plate & 2 & heat up to & 160 \\
& & $1.12^{\prime}$ & keep constant on & 160 \\
& upper plate & $1.20^{\prime}$ & cool down to & 110 \\
& & $1.30^{\prime}$ & keep constant on & 110 \\
& 1 & keep constant on & 90
\end{tabular}

\section{Digestion}

(with $2 \mathrm{~mL}$ sub-boiled $\mathrm{HNO}_{3}$ (distilled $65 \%$, p.a., Merck), $1 \mathrm{~mL}$ sub-boiled $\mathrm{HF}$ (40\%, suprapure, Merck) and $2 \mathrm{~mL} \mathrm{H}_{2} \mathrm{O}_{2}(30 \%$, suprapure, Merck))

\begin{tabular}{ccccc} 
Programme & heating plate & time (hours) & command & Temperature $\left({ }^{\circ} \mathrm{C}\right)$ \\
\hline digestion & bottom plate & 1 & heat up to & 100 \\
& 5 & keep constant on & 100 \\
& 1 & heat up to & 120 \\
& 2 & keep constant on & 120 \\
& 1 & heat up to & 140 \\
& 2 & keep constant on & 140 \\
1 & heat up to & 160 \\
2 & keep constant on & 160 \\
& 1 & heat up to & 180 \\
& 4 & keep constant on & 180 \\
& 2 & heat up to & 210 \\
& 7 & keep constant on & 210 \\
& 2 & keep constant on & 170 \\
& 2 & keep constant on & 160 \\
& $1.30^{\prime}$ & keep constant on & 140
\end{tabular}

Concentration of samples after digestion

\begin{tabular}{ccccc} 
Programme & heating plate & time (hours) & command & Temperature $\left({ }^{\circ} \mathrm{C}\right)$ \\
\hline concentration & bottom plate & 2 & heat up to & 160 \\
& & $0.32^{\prime}$ & keep constant on & 160 \\
& upper plate & $1.20^{\prime}$ & heat up to & 110 \\
& & $1.30^{\prime}$ & keep constant on & 110 \\
& & 1 & keep constant on & 90
\end{tabular}


Table S2: Analysed isotopes with natural abundances and potential interference species, which are taken into account for evaluating ICP-TOF-MS data.

\begin{tabular}{|c|c|c|c|}
\hline \multicolumn{2}{|r|}{ Analyte } & \multicolumn{2}{|c|}{ Potential Interferences } \\
\hline Isotope & Abundance $(\%)$ & Species & Abundance $(\%)^{\mathrm{a}}$ \\
\hline${ }^{139} \mathrm{La}$ & 99.91 & & \\
\hline${ }^{140} \mathrm{Ce}$ & 88.48 & & \\
\hline${ }^{141} \operatorname{Pr}$ & 100 & & \\
\hline${ }^{142} \mathrm{Nd}$ & 27.13 & ${ }^{142} \mathrm{Ce}$ & 11.08 \\
\hline${ }^{143} \mathrm{Nd}$ & 12.18 & & \\
\hline${ }^{144} \mathrm{Nd}$ & 23.8 & ${ }^{144} \mathrm{Sm}$ & 3.1 \\
\hline${ }^{145} \mathrm{Nd}$ & 8.3 & & \\
\hline${ }^{146} \mathrm{Nd}$ & 17.19 & & \\
\hline${ }^{147} \mathrm{Sm}$ & 15 & & \\
\hline${ }^{149} \mathrm{Sm}$ & 13.8 & & \\
\hline${ }^{152} \mathrm{Sm}$ & 26.7 & & \\
\hline${ }^{151} \mathrm{Eu}$ & 47.8 & & \\
\hline${ }^{153} \mathrm{Eu}$ & 52.2 & & \\
\hline${ }^{155} \mathrm{Gd}$ & 14.8 & ${ }^{139} \mathrm{La}^{16} \mathrm{O}$ & 99.67 \\
\hline${ }^{156} \mathrm{Gd}$ & 20.47 & ${ }^{140} \mathrm{Ce}^{16} \mathrm{O}$ & 88.26 \\
\hline${ }^{157} \mathrm{Gd}$ & 15.65 & ${ }^{141} \operatorname{Pr}^{16} \mathrm{O}$ & 99.76 \\
\hline${ }^{158} \mathrm{Gd}$ & 24.84 & ${ }^{142} \mathrm{Nd}^{16} \mathrm{O}$ & 27.09 \\
\hline & & ${ }^{142} \mathrm{Ce}^{16} \mathrm{O}$ & 11.05 \\
\hline${ }^{159} \mathrm{~Tb}$ & 100 & ${ }^{143} \mathrm{Nd}^{16} \mathrm{O}$ & 12.15 \\
\hline${ }^{161}$ Dy & 18.9 & ${ }^{145} \mathrm{Nd}^{16} \mathrm{O}$ & 8.28 \\
\hline${ }^{163}$ Dy & 24.9 & ${ }^{147} \mathrm{Sm}^{16} \mathrm{O}$ & 14.96 \\
\hline${ }^{164} \mathrm{Dy}$ & 28.2 & ${ }^{148} \mathrm{Sm}^{16} \mathrm{O}$ & 11.27 \\
\hline & & ${ }^{148} \mathrm{Nd}^{16} \mathrm{O}$ & 5.75 \\
\hline & & ${ }^{164} \mathrm{Er}$ & 1.61 \\
\hline${ }^{165} \mathrm{Ho}$ & 100 & ${ }^{149} \mathrm{Sm}^{16} \mathrm{O}$ & 13.77 \\
\hline${ }^{166} \mathrm{Er}$ & 33.6 & ${ }^{150} \mathrm{Nd}^{16} \mathrm{O}$ & 5.63 \\
\hline${ }^{167} \mathrm{Er}$ & 22.95 & ${ }^{151} \mathrm{Eu}^{16} \mathrm{O}$ & 47.69 \\
\hline${ }^{168} \mathrm{Er}$ & 26.8 & ${ }^{152} \mathrm{Sm}^{16} \mathrm{O}$ & 26.64 \\
\hline${ }^{169} \mathrm{Tm}$ & 100 & ${ }^{153} \mathrm{Eu}^{16} \mathrm{O}$ & 52.07 \\
\hline${ }^{171} \mathrm{Yb}$ & 14.3 & ${ }^{155} \mathrm{Gd}^{16} \mathrm{O}$ & 14.76 \\
\hline${ }^{172} \mathrm{Yb}$ & 21.9 & ${ }^{156} \mathrm{Gd}^{16} \mathrm{O}$ & 20.42 \\
\hline${ }^{173} \mathrm{Yb}$ & 16.12 & ${ }^{157} \mathrm{Gd}^{16} \mathrm{O}$ & 15.61 \\
\hline${ }^{174} \mathrm{Yb}$ & 31.8 & ${ }^{158} \mathrm{Gd}^{16} \mathrm{O}$ & 24.78 \\
\hline${ }^{175} \mathrm{Lu}$ & 100 & ${ }^{159} \mathrm{~Tb}^{16} \mathrm{O}$ & 99.76 \\
\hline
\end{tabular}









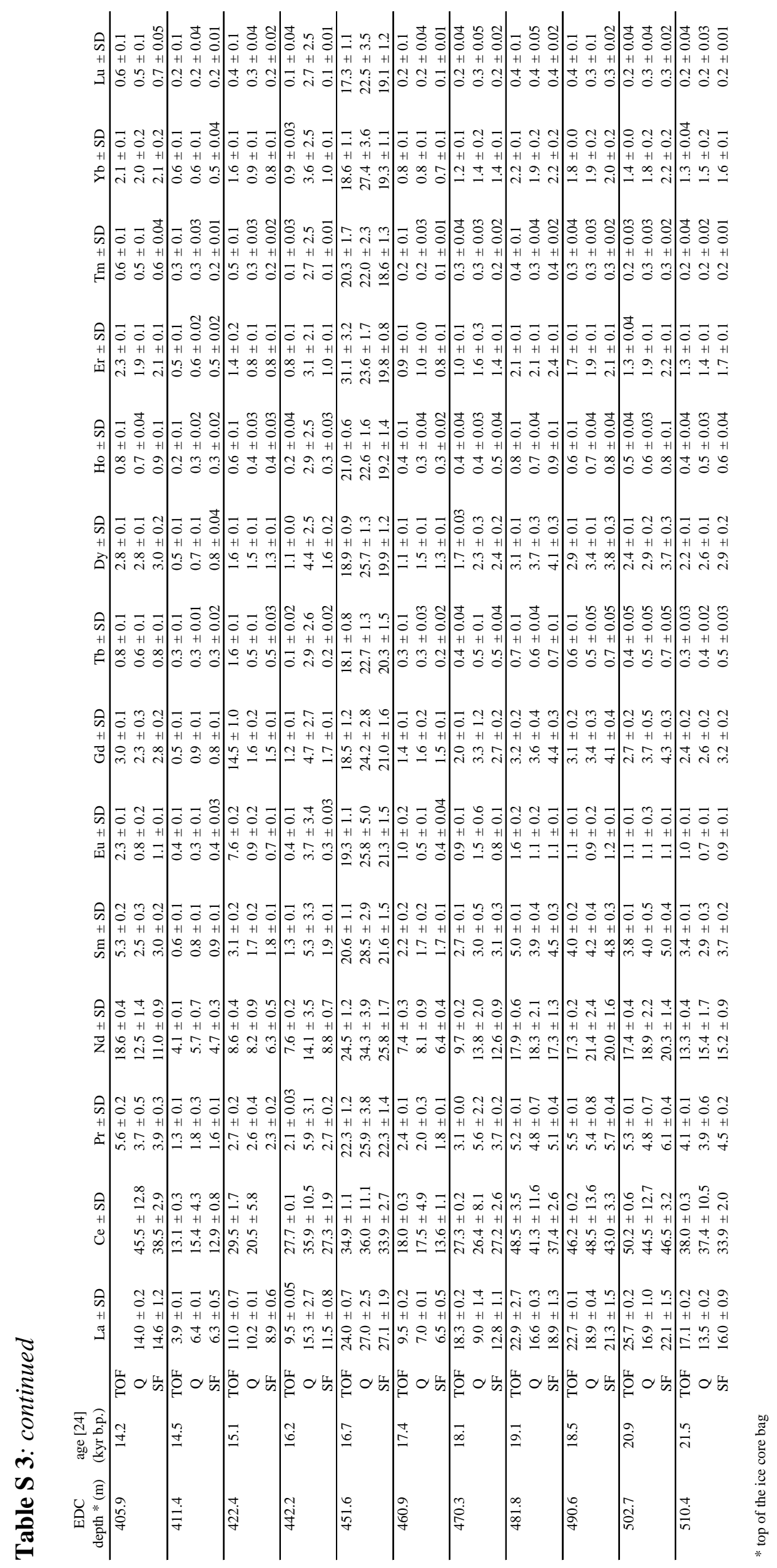

